\title{
Temperature Dependent Elastic and Ultrasonic Properties of Iron Aluminide
}

\author{
A. K. Yadav ${ }^{1}$, Devraj Singh ${ }^{2, *}$, Sudhanshu Tripathi ${ }^{3}$, Vyoma Bhalla $^{2}$, R. R. Yadav ${ }^{4}$ \\ ${ }^{1}$ Department of Applied Physics, Babasaheb Bhimrao Ambedkar University, Lucknow-226025, India \\ ${ }^{2}$ Department of Applied Physics, Amity School of Engineering and Technology, Bijwasan, New Delhi-110061, India \\ ${ }^{3}$ Department of Instrumentation and Control Engineering, Amity School of Engineering and Technology, Bijwasan, New Delhi-110061, \\ India \\ ${ }^{4}$ Department of Physics, University of Allahabad, Allahabad-211002, India \\ *Corresponding author: dsingh13@amity.edu
}

Copyright (C 2013 Horizon Research Publishing All rights reserved.

\begin{abstract}
The anisotropic elastic constants of a B2 structured iron aluminide $\mathrm{FeAl}(\mathrm{Fe}-40$ at. \% $\mathrm{Al})$ alloy at different temperatures are computed using Coulomb and Born Mayer model. The temperature dependent ultrasonic properties of the alloy along with other associated parameters are determined using the elastic constants. The correlation between the mechanical and thermal properties makes ultrasonic properties a suitable, nondestructive tool to study the physical state of $\mathrm{FeAl}$ alloy. The results of present investigation are discussed in correlation with the microstructural phenomenon like phonon-phonon interaction and the other thermophysical properties. Temperature dependence of ultrasonic attenuation along different crystallographic directions reveals some typical characteristic features.
\end{abstract}

Keywords Iron Aluminides, Elastic Properties, Non Destructive Evaluation

\section{Introduction}

The growing importance of intermetallic compounds as materials for high-temperature applications has provoked intense research on structural, mechanical and thermal properties [1-3]. Many intermetallic alloys remain strong at high temperatures yet ductile at low temperatures. Of particular interest are the transitional metal aluminides e.g. $\mathrm{FeAl}, \mathrm{NiAl}$ and $\mathrm{CoAl}$, which are resistant to corrosion and oxidation, have interesting magnetic properties [4], and are used as high-temperature structural materials and soft magnetic materials. In addition, their high electrical resistivity which increases with temperature and low cost of production have made these intermetallics excellent candidates for various applications such as heating elements, insulation wrapping, tooling, catalytic converters, automotive exhaust manifolds, fabric and paper cutting, piping, and hot gas filters [5-9].

Iron aluminides $(\mathrm{FeAl})$ have been a subject of renewed attention in the recent past. Although the iron aluminum phase diagram exhibits several intermetallics phases at varying compositions and temperatures, namely $\mathrm{B} 2$ and $\mathrm{DO}_{3}$ predominate the field with stability over wide range of composition. $\mathrm{FeAl}$ has an ordered $\mathrm{B} 2 \mathrm{CsCl}$ structure, where central $\mathrm{Fe}$ atom has eight $\mathrm{Fe}$ neighbours, while each of the corner $\mathrm{Fe}$ atoms in the cube have one $\mathrm{Fe}$ and other $\mathrm{Al}$ atoms. An expansion of lattice as compared to bulk $\mathrm{Fe}$ is expected since the ionic radius of $\mathrm{Al}(1.43 \stackrel{0}{\mathrm{~A}})$ is larger than the corresponding value of $\mathrm{Fe}$ which is equal to $1.27 \mathrm{~A}$ [10].

In the past years, considerable efforts have been made to understand the processing and mechanical properties of these ordered phases with an aim to increase strength, ductility and corrosion resistance. While these efforts imparted significant knowledge on their mechanical behavior [11], an understanding of their ultrasonic properties is still limited due to lack of substantial attention. Efficient utilization of iron aluminide requires a good understanding of thermophysical and ultrasonic properties for high temperature applications and for finite element modeling of their behavior in the temperature range of interest. The ultrasonic properties are well correlated to micro structural and thermophysical properties of the materials [12]. Therefore, we have established a theoretical approach for the determination of the temperature dependent ultrasonic attenuation, thermal relaxation time and non-linearity parameters in FeAl. Elastic properties of the material are required for the evaluation of ultrasonic properties. Therefore, we have also calculated anisotropic elastic properties of $\mathrm{FeAl}(\mathrm{Fe}-40$ at.\% $\mathrm{Al})$ at different thermal conditions. Finally, we have made attempt to correlate the ultrasonic properties with the thermophysical and mechanical properties of the compound for the characterization.

\section{Computational Methods}




\subsection{Method for the Non-Linear Elastic Constants}

We have used Coulomb and Born-Mayer short range repulsive potential for the formulation of higher order elastic constants. This potential is given by

$$
\varphi_{\mu \nu}(r)= \pm\left(e^{2} / r\right)+A \exp (-r / b)=\varphi(r)
$$

here $\mathrm{e}$ is electronic charge, $\mathrm{A}$ and $\mathrm{b}$ are pre- exponential and hardness parameter. Following Brügger's definition [13], we can write the elastic constant of the $\mathrm{n}^{\text {th }}$ order as:

$$
\mathrm{C}_{\mathrm{ijklmn}} \cdots=\left(\partial^{\mathrm{n}} \mathrm{F} / \partial \eta_{\mathrm{ij}} \partial \eta_{\mathrm{kl}} \partial \eta_{\mathrm{mn}} \ldots\right)
$$

here $\mathrm{F}$ refers to free energy density of undeformed material and $\eta_{i j}$ is lagrangian strain components tensor. In the present investigation, Voigt notation $\mathrm{C}_{\mathrm{IJK}}$... have been used instead of tensor notation $\mathrm{C}_{\mathrm{ijk} l \mathrm{mn} . . .}$. The total free energy density $\mathrm{F}$ expanded in terms of strain $\eta$, can be written (using Taylor's series expansion) as:

$$
\mathrm{F}=\sum_{\mathrm{n}=0}^{\infty} \mathrm{F}_{\mathrm{n}}=\sum_{\mathrm{n}=0}^{\infty} \frac{1}{n !}\left(\partial^{\mathrm{n}} \mathrm{F} / \partial \eta_{\mathrm{ij}} \partial \eta_{\mathrm{kl}} \partial \eta_{\mathrm{mn}} \cdots\right) \eta_{\mathrm{ij}} \eta_{\mathrm{kl}} \eta_{\mathrm{mn}} \cdots
$$

The free energy density of a crystal at a finite temperature $\mathrm{T}$ is given as [14]:

$$
\mathrm{F}=\mathrm{U}+\mathrm{F}^{\mathrm{Vib}}
$$

here $U$ is the internal energy of unit volume of the crystal when all atoms (ions) are at rest on their lattice point. $\mathrm{F}^{\mathrm{Vib}}$ is the vibrational free energy density. Thus the elastic constants can be separated in to two parts.

$$
\mathrm{C}_{\mathrm{IJK} \ldots}=\mathrm{C}_{\mathrm{IJK} \ldots}^{0}+\mathrm{C}_{\mathrm{IJK} \ldots .}^{\mathrm{Vib}}
$$

The first and the second ones are strain derivatives of $U$ and $\mathrm{F}^{\mathrm{vib}}$, and they represent the 'static' and 'vibrational' elastic constants.

The obtained expressions for second and third order elastic constants at $0 \mathrm{~K}$ are:

$$
\left.\begin{array}{l}
\mathrm{C}_{11}^{0}=\frac{3}{8} \frac{\mathrm{e}^{2}}{\mathrm{r}_{0}^{4}} \mathrm{~S}_{5}^{(2)}+\frac{3 \phi\left(\mathrm{r}_{1}\right)}{\mathrm{br}_{0}}\left(\frac{\sqrt{3}}{3 \mathrm{r}_{0}}+\frac{1}{\mathrm{~b}}\right)+\frac{2 \phi\left(\mathrm{r}_{2}\right)}{\mathrm{br}_{0}}\left(\frac{1}{2 \mathrm{r}_{0}}+\frac{1}{\mathrm{~b}}\right) \\
\mathrm{C}_{12}^{0}=\mathrm{C}_{44}^{0}=\frac{3}{8} \frac{\mathrm{e}^{2}}{\mathrm{r}_{0}^{4}} \mathrm{~S}_{5}^{(1,1)}+\frac{\phi\left(\mathrm{r}_{2}\right)}{\mathrm{br}_{0}}\left(\frac{1}{2 \mathrm{r}_{0}}+\frac{1}{\mathrm{~b}}\right) \\
\mathrm{C}_{111}^{0}=-\frac{15}{8} \frac{\mathrm{e}^{2}}{\mathrm{r}_{0}^{4}} \mathrm{~S}_{7}^{(3)}-\frac{\phi\left(\mathrm{r}_{1}\right)}{9 \mathrm{~b}}\left(\frac{\sqrt{3}}{\mathrm{r}_{0}^{2}}+\frac{3}{\mathrm{br}_{0}}+\frac{\sqrt{3}}{\mathrm{~b}^{2}}\right)-\frac{\phi\left(\mathrm{r}_{2}\right)}{2 \mathrm{~b}}\left(\frac{3}{\mathrm{r}_{0}^{2}}+\frac{6}{\mathrm{br}_{0}}+\frac{4}{\mathrm{~b}^{2}}\right) \\
\mathrm{C}_{112}^{0}=\mathrm{C}_{166}^{0}=-\frac{15}{8} \frac{\mathrm{e}^{2}}{\mathrm{r}_{0}^{4}} \mathrm{~S}_{7}^{(2,1)}-\frac{\phi\left(\mathrm{r}_{1}\right)}{9 \mathrm{~b}}\left(\frac{\sqrt{3}}{\mathrm{r}_{0}^{2}}+\frac{3}{\mathrm{br}_{0}}+\frac{\sqrt{3}}{\mathrm{~b}^{2}}\right) \\
\mathrm{C}_{123}^{0}=\mathrm{C}_{456}^{0}=\mathrm{C}_{144}^{0}=-\frac{15}{8} \frac{\mathrm{e}^{2}}{\mathrm{r}_{0}^{4}} \mathrm{~S}_{7}^{(1,1,1)}-\frac{\phi\left(\mathrm{r}_{1}\right)}{9 \mathrm{~b}}\left(\frac{\sqrt{3}}{\mathrm{r}_{0}^{2}}+\frac{3}{\mathrm{br}_{0}}+\frac{\sqrt{3}}{\mathrm{~b}^{2}}\right)
\end{array}\right\}
$$

where $\phi\left(\mathrm{r}_{1}\right)=\mathrm{A} \exp \left(-\mathrm{r}_{1} / \mathrm{b}\right), \phi\left(\mathrm{r}_{2}\right)=\mathrm{A} \exp \left(-\mathrm{r}_{2} / \mathrm{b}\right)$, $\mathrm{r}_{1}=\sqrt{3} \mathrm{r}_{0}, \mathrm{r}_{2}=2 \mathrm{r}_{0}$ and $\mathrm{S}$ is the lattice sum. The hardness parameter $\mathrm{b}$ can be evaluated using Hinderbr and equation and one can use directly the evaluated values of $b$ for cubic crystals [15-18]. The value of A can be obtained with the equilibrium condition and is given as:

$$
\mathrm{A}=\left(\mathrm{bZ}_{0} \mathrm{e}^{2} / \mathrm{r}_{0}^{2}\right)\left[8 \sqrt{3} \exp \left(-\mathrm{r}_{1} / \mathrm{b}\right)+12 \exp \left(-\mathrm{r}_{2} / \mathrm{b}\right)\right\rfloor
$$

For the evaluation of vibrational part of SOEC and TOEC, we can write the vibrational energy density at temperature $\mathrm{T}$ as:

$$
\mathrm{F}^{\mathrm{Vib} .}=\mathrm{kT} \sum_{\mathrm{i}=1}^{3 \mathrm{sN}} \ln 2 \operatorname{Sinh}\left\{\hbar \omega_{\mathrm{i}} / 2 \mathrm{kT}\right\}
$$

For $\mathrm{h} \omega_{\mathrm{i}}<<\mathrm{kT}[16,19]$ it becomes

$$
\mathrm{F}^{\mathrm{Vib}}=\mathrm{kT} \sum_{\mathrm{i}=1}^{3 \mathrm{sN}} \ln \left(\hbar \omega_{\mathrm{i}} / \mathrm{kT}\right)
$$

Elastic constants SOEC and TOEC at temperature T can be written as:

$$
\mathrm{C}_{\mathrm{IJ}}=\mathrm{C}_{\mathrm{IJ}}^{\mathrm{o}}+\mathrm{C}_{\mathrm{IJ}}^{\mathrm{Vib}}
$$

And

$$
\mathrm{C}_{\mathrm{IJK}}=\mathrm{C}_{\mathrm{IJK}}^{\mathrm{o}}+\mathrm{C}_{\mathrm{IJK}}^{\mathrm{Vib}}
$$

where

$$
\begin{gathered}
\mathrm{C}_{\mathrm{IJ}}^{\mathrm{Vib}}=\mathrm{A}_{\mathrm{IJ}} \mathrm{T} \text { and } \mathrm{A}_{\mathrm{IJ}}=1_{1} \mathrm{k}\left|\frac{\partial \mathrm{C}_{\mathrm{IJ}}^{0}}{\partial \mathrm{r}}\right|_{\mathrm{r}=\mathrm{r}_{0}}+\frac{\mathrm{f}_{\mathrm{IJ}}^{\mathrm{Vib}}}{\mathrm{TV}_{\mathrm{C}}} \\
\mathrm{C}_{\mathrm{IJK}}^{\mathrm{Vib}}=\mathrm{A}_{\mathrm{IJK}} \mathrm{T} \text { and } \mathrm{A}_{\mathrm{IJK}}=1_{1} \mathrm{k}\left|\frac{\partial \mathrm{C}_{\mathrm{IJK}}^{0}}{\partial \mathrm{r}}\right|_{\mathrm{r}=\mathrm{r}_{0}}+\frac{\mathrm{f}_{\mathrm{IJK}}^{\mathrm{Vib}}}{\mathrm{TV}_{\mathrm{C}}}
\end{gathered}
$$

The Eqs. (11) and (12) evaluate the vibrational part of elastic constants at finite temperature, whose addition to static part of elastic constants calculated with Eq. (5) gives the elastic constants at a particular temperature

\subsection{Method for the Ultrasonic Attenuation}

For the evaluation of ultrasonic attenuation, we have used the phonon phonon interaction mechanism given by Mason and Bateman approach. The ultrasonic attenuation over frequency square $\left({ }^{2}\right)$ Ni像 (Akhieser type loss) due to phonon- phonon interaction mechanism at $\omega \tau<<1$ is expressed as $[20,21]$ :

$$
\left(\alpha / \mathrm{f}^{2}\right) \text { Akh. }=\frac{\mathrm{E}_{\mathrm{O}}(\mathrm{D} / 3) 4 \pi^{2} \tau}{2 \rho \mathrm{V}^{3}}
$$

where

$$
\mathrm{D}=9<\left(\gamma_{i}^{\mathrm{j}}\right)^{2}>-3<\gamma_{\mathrm{i}}^{\mathrm{j}}>^{2} \frac{\mathrm{C}_{\mathrm{V}} \mathrm{T}}{\mathrm{E}_{\mathrm{o}}}
$$

here $\mathrm{D}$ and $\mathrm{V}$ are the non-linearity parameter and velocity of ultrasonic wave for longitudinal and shear wave, $E_{0}$ and $C_{v}$ are thermal energy density and the specific heat per unit volume respectively. Grüneisen parameters are the ratio of elastic constants (SOECs and TOECs). Expressions for 
Grüneisen parameters are available in literature[21]. < $\gamma_{\mathrm{i}}^{\mathrm{j}}>$,the average Grüneisen no., is determined using SOEC/TOEC. The thermal relaxation time $(\tau)$ is given as:

$$
\tau=\tau_{\mathrm{S}}=\tau_{\mathrm{L}} / 2=\frac{3 \mathrm{~K}}{\mathrm{C}_{\mathrm{V}} \mathrm{V}_{\mathrm{D}}^{2}}
$$

where $\mathrm{K}$ is the thermal conductivity and $\mathrm{V}_{\mathrm{D}}$ is the Debye average velocity of ultrasonic wave as:

$$
\frac{3}{V_{D}^{3}}=\frac{1}{V_{L}^{3}}+\frac{2}{V_{S}^{3}}
$$

Thermoelastic loss is obtained by the expression as:

$$
\left(\alpha / \mathrm{f}^{2}\right)_{\text {th. }}=\frac{4 \pi^{2}<\gamma_{\mathrm{i}}^{\mathrm{j}}>^{2} \mathrm{KT}}{2 \rho \mathrm{V}_{\mathrm{L}}^{5}}
$$

\section{Results and Discussion}

The nearest neighbor distance' $\mathrm{r}_{0}$ ' for the $\mathrm{FeAl}(\mathrm{Fe}-40$ at $\%$ $\mathrm{Al})$ is $2.91 \mathrm{~A}^{0}$ [20] and value of hardness parameter is 0.169 $\mathrm{A}^{0}$. Computed values of Second - and third -order constants (SOEC and TOEC) at different temperatures are presented in Table 1 . Thermal conductivity $\mathrm{K}$ at different temperatures is taken from the literature [12]. The value of specific heat per unit volume $\left(\mathrm{C}_{\mathrm{V}}\right)$ and thermal energy density $\left(\mathrm{E}_{0}\right)$ are evaluated using $\theta_{\mathrm{D}} / \mathrm{T}$ physical constant table from AIP Handbook [22]. The temperature dependence of density $(\rho)$ of this material is evaluated with help of literature [23].The values of density $(\rho), \mathrm{K}, \mathrm{C}_{\mathrm{V}}$ and $\mathrm{E}_{0}$ are presented in Table 2 .

The ultrasonic velocities for longitudinal and shear waves are calculated using SOEC and density. Thermal relaxation time $(\tau)$ is calculated by Eq. (15) using thermal conductivity data and Debye average velocity calculated using the Eqn. (16) at different temperatures. The calculated ultrasonic velocities, Debye average velocity $\left(V_{D}\right)$ and Thermal relaxation time $(\tau)$ at different temperatures are shown in Figure.1.

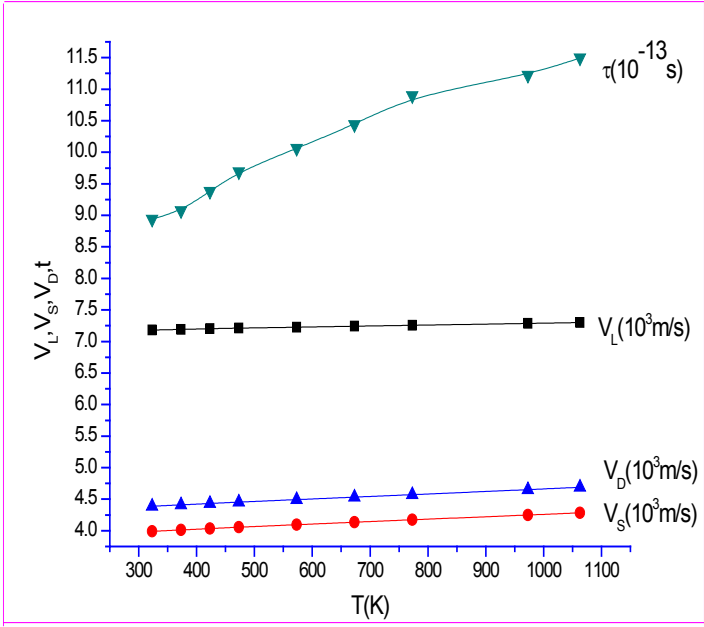

Figure 1. $\mathrm{V}_{\mathrm{L}}, \mathrm{V}_{\mathrm{S}}, \mathrm{V}_{\mathrm{D}}, \tau$ vs temperature
Ultrasonic Grüneisen parameters (UGP) are an important property of the material, which gives thermal behavior of that particular material. The UGP can be obtained with SOEC and TOEC using the Mason's Table [18]. The present values of SOEC and bulk modulus B with the others [24,25] are given in Table 3.These Parameters at different temperature are presented in Table 4. The values of ultrasonic coupling constants for longitudinal and shear waves are computed using Eq.(14) and presented in Table 4. The computed values of ultrasonic attenuation $\left(\alpha / f^{2}\right)_{\text {th. }}$, $\left(\alpha / \mathrm{f}^{2}\right)_{\text {Akh.Long }}$ for longitudinal wave and $\left(\alpha / \mathrm{f}^{2}\right)_{\text {Akh.Shear }}$ for shear wave are plotted in Figures.2-4. The value of bulk modulus B $=\left(\mathrm{C}_{11}+2 \mathrm{C}_{12}\right) / 3$ determined by the interaction potential model is $121.0 \mathrm{GPa}$. Yang et al. [27] calculated the bulk modulus $\mathrm{B}=116.0 \mathrm{GPa}$ using tight binding total energy calculations. Although our values differ by $30-36 \%$ of the previous value $[27,28]$, but order of the SOECs are same. This difference occurs due to different approach. Here we have used simple approach i.e. Coulomb and Born-Mayer potential to find elastic constants upto second nearest neighbourhood. While Yang et.al used a tight bonding total energy method and Leemy et. al., gave experimental results of elastic constants. Thus, there is good agreement between the present value and others [24,25]. Similarly present value of the shear modulus $\mu=\left(\mathrm{C}_{11}-\mathrm{C}_{12}+\mathrm{C}_{44}\right) / 3$ is $55.8 \mathrm{GPa}$ and the shear modulus deduced from extrapolation in

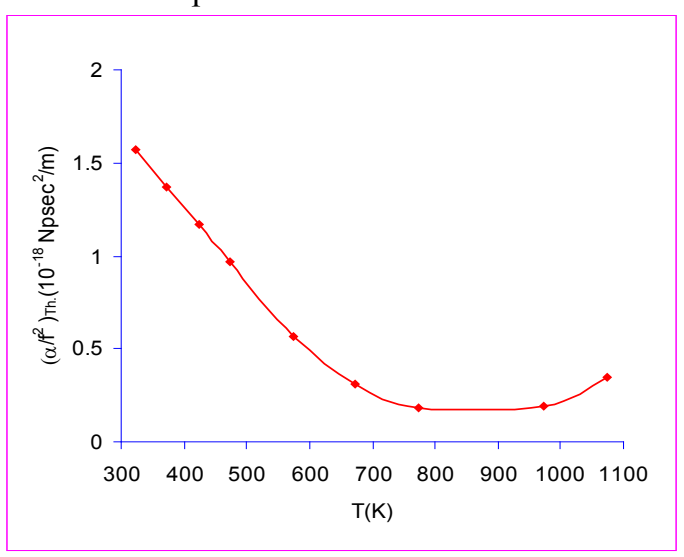

Figure 2. $\left(\alpha / \mathrm{f}^{2}\right)_{\text {th. }}$ Vs temperature

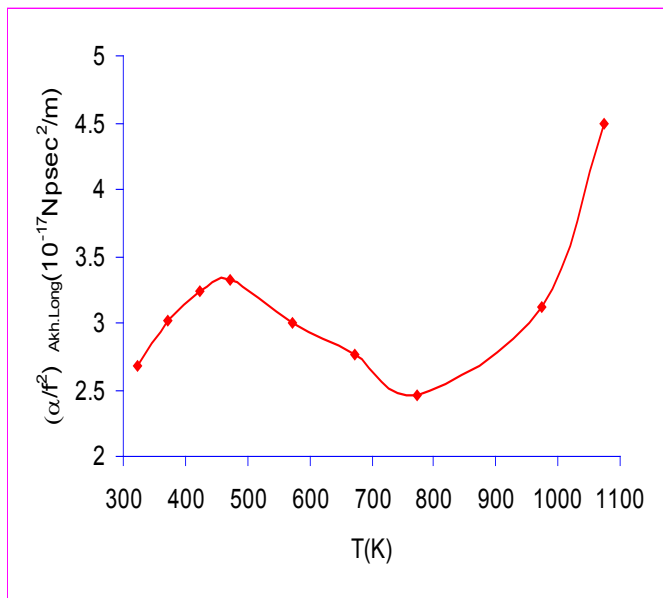

Figure 3. $\left(\alpha / \mathrm{f}^{2}\right)_{\text {Akh.long vs }}$ temperature 


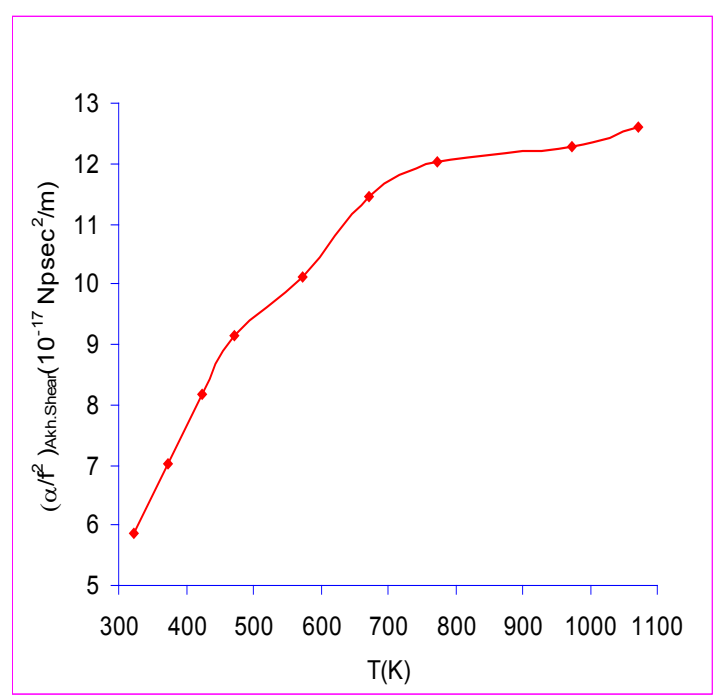

Figure 4. $\left(\alpha / \mathrm{f}^{2}\right)_{\text {Akh.shear }}$ VS temperature

literature [28] is $73.0 \mathrm{GPa}$ and that the value calculated by Junqua et al. [29] is 92.0 GPa. Hence, our present value of shear modulus is comparable to others. The higher order elstic constants (SOECs and TOECs) have the same nature as obtained in our previous study of b.c.c. intermetallics. Thus our theoretical approach for calculation of higher order elastic constants seems justified and well established. The stability criterion of the chosen material is satisfied as this material fulfilled the following conditions.

$$
\mathrm{B}_{\mathrm{T}}=\frac{\mathrm{C}_{11}+2 \mathrm{C}_{12}}{3}>0, \mathrm{C}_{44}>0 \text {, and } \mathrm{C}_{\mathrm{S}}=\frac{\mathrm{C}_{11}-\mathrm{C}_{12}}{2}>0
$$

where CIJ =conventional SOEC, BT=Bulk Modulus, $\mathrm{C} 44=$ Shear modulus, $\mathrm{CS}=$ Tetragonal modulus. Here we see that $\frac{\mathrm{dC}_{\mathrm{ij}}}{\mathrm{dT}}$ slopes are positive. This shows deviation of Cauchy's relation.Figure.1 reveals that ultrasonic velocities and thermal relaxation time increases as temperature increases. This nature is very similar to other investigations on cubic crystals [32-35,36]. The order of ultrasonic velocities for longitudinal and shear waves is found same as our previous study on intermetallics[31]. Figure. 1 also shows that the order of thermal relaxation time $\left(\tau_{\mathrm{th}}\right)$ for FeAl is 10-13 second, which is same as in other intermetallics[31-34].this signifies that the circulation of thermal phonon maintain its equilibrium location in $10^{-13} \mathrm{~s}$ after passing the ultrasonic wave. Although this is less time than the other metallic alloys[15].SOEC and TOEC are used to obtain average ultrasonic Grüneisen parameters (UGP) along $<100>$ direction for longitudinal wave over 39 modes and for shear wave 18 modes. These UGP as given in Table 3, are applied to find out the acoustic coupling constant. The acoustic coupling constant is the measure of acoustic energy conveted into thermal energy and plays a very important role to characterize any material. A careful examination of the Figure. 2 reveals that the ultrasonic attenuation due to thermal relaxation process decreases very rapidly from $323 \mathrm{~K}$ to $773 \mathrm{~K}$ and then it is almost saturated. Ultrasonic attenuation due to phonon- phonon interaction (Akhiezer type loss) for longitudinal wave increases from $323 \mathrm{~K}$ to $473 \mathrm{~K}$ and then decreases up to $773 \mathrm{~K}$, then there is a sharp rise of attenuation up to $1063 \mathrm{~K}$. A perusal of Figure. 4 shows that the attenuation due to phonon-phonon interaction for shear wave increases linearly from $323 \mathrm{~K}$ to $773 \mathrm{~K}$, beyond that there is gradual rise in attenuation. Acoustic coupling constant depend on elastic constants through Grüneisen number, specific heat per unit volume and thermal energy density.

On careful observation of Figure. 2 through Eq. (15) it may be stated that $\left(\alpha / \mathrm{f}^{2}\right)_{\mathrm{Akh} \text {. for longitudinal wave decreases }}$ because of decrease in acoustic coupling constant $D_{L}$ up to $773 \mathrm{~K}$ after then it is predominantly affected by thermal energy density. Temperature dependency of the ultrasonic attenuation for shear wave is correlated to the behaviour of temperature dependent thermal energy density of the material. From Figure. 2 it reveals that ultrasonic attenuation due to thermoelastic loss is mainly affected by the elastic constants through Grüneisen parameter. Behaviour of ultrasonic attenuation due to phonon-phonon interaction at $\mathrm{T}=473 \mathrm{~K}$ is very interesting for the longitudinal wave. In both polycrystalline and single crystal forms, FeAl is brittle at room temperature and ductile at higher temperature. Many intermetallic phases show a transition from a brittle to ductile behaviour when the temperature is increased. The change from brittle to ductile behaviour can occur gradually with increasing temperature or within a very limited temperature range of $100{ }^{\circ} \mathrm{C}$ or less [36]. There is abrupt increase in ductility in $\mathrm{FeAl}$ over a small temperature range near the brittle to ductile transition temperature (BDTT) (473K) [37]. Here ultrasonic attenuation due to phonon-phonon interaction for longitudinal wave decreases very rapidly around BDTT (473K). Thus the temperature variation of ultrasonic attenuation seems to predict the abrupt change in ductility at the BDTT. The reasons for such abrupt change in ductility may be dislocation climb, thermally activated slip, change of fracture mode and additional slips. 
Table 1. SOEC and TOEC $\left(10^{10} \mathrm{~N} / \mathrm{m}^{2}\right)$ of FeAl in the temperature range $323 \mathrm{~K}-1063 \mathrm{~K}$.

\begin{tabular}{|c|c|c|c|c|c|c|c|c|c|}
\hline \multirow{2}{*}{$\begin{array}{c}\mathrm{EC} \\
\rightarrow \\
\mathrm{T} . \\
{[\mathrm{K}] \downarrow}\end{array}$} & \multicolumn{3}{|c|}{ SOEC } & \multicolumn{6}{|c|}{ TOEC } \\
\hline & C11 & $\mathrm{C} 12$ & C44 & C111 & $\mathrm{C} 112$ & $\mathrm{C} 123$ & C144 & C166 & C456 \\
\hline 323 & 19.317 & 8.492 & 5.964 & -157.90 & -47.89 & -40.88 & -31.24 & -36.95 & -40.95 \\
\hline 373 & 19.338 & 8.484 & 6.017 & -155.14 & -47.30 & -40.22 & -29.10 & -34.68 & -40.31 \\
\hline 423 & 19.360 & 8.475 & 6.072 & -152.37 & -46.72 & -39.57 & -26.95 & -32.59 & -39.67 \\
\hline 473 & 19.382 & 8.466 & 6.126 & -149.60 & -46.14 & -38.92 & -24.80 & -30.12 & -39.02 \\
\hline 573 & 19.425 & 8.449 & 6.234 & -144.07 & -44.98 & -37.61 & -20.51 & -25.58 & -37.74 \\
\hline 673 & 19.468 & 8.432 & 6.342 & -138.54 & -43.82 & -36.23 & -16.22 & -21.03 & -36.45 \\
\hline 773 & 19.511 & 8.414 & 6.450 & -133.00 & -42.65 & -34.99 & -11.93 & -16.48 & -35.12 \\
\hline 973 & 19.596 & 8.380 & 6.665 & -121.93 & -40.32 & -32.37 & -3.34 & -7.38 & -32.59 \\
\hline 1063 & 19.635 & 8.365 & 6.763 & -116.95 & -39.27 & -31.19 & 0.53 & -3.28 & -31.43 \\
\hline
\end{tabular}

Table 2. Thermal Conductivity $(\mathrm{K})$, density $(\rho)$, specific heat/volume $\left(\mathrm{C}_{\mathrm{V}}\right)$ and thermal energy density $\left(\mathrm{E}_{0}\right)$ of FeAl in the temperature range $323-1063 \mathrm{~K}$

\begin{tabular}{|c|c|c|c|c|}
\hline $\mathrm{T}[\mathrm{K}]$ & $\mathrm{K}(\mathrm{J} / \mathrm{sec} . \mathrm{m} . \mathrm{K})$ & $\rho\left(10^{3} \mathrm{Kg} / \mathrm{m}^{3}\right)$ & $\mathrm{C}_{\mathrm{V}} \times 10^{6}\left(\mathrm{~J} / \mathrm{m}^{3} \mathrm{~K}\right)$ & $\begin{array}{c}\mathrm{E}_{0} \mathrm{X} \\
10^{8} / \mathrm{J}^{3} \mathrm{3}\end{array}$ \\
\hline 323 & 10.2 & 3.745 & 1.779 & 3.128 \\
\hline 373 & 10.8 & 3.739 & 1.837 & 4.042 \\
\hline 423 & 11.6 & 3.733 & 1.890 & 4.985 \\
\hline 473 & 12.4 & 3.726 & 1.936 & 5.924 \\
\hline 573 & 13.4 & 3.719 & 1.978 & 7.562 \\
\hline 673 & 14.4 & 3.712 & 2.013 & 9.876 \\
\hline 773 & 15.4 & 3.705 & 2.027 & 11.835 \\
\hline 973 & 16.6 & 3.692 & 2.051 & 15.894 \\
\hline 1063 & 17.3 & 3.684 & 2.054 & 17.676 \\
\hline
\end{tabular}

Table 3. Elastic properties (in $10^{10} \mathrm{Nm}^{-2}$ ) of $\mathrm{FeAl}$ at temperature $300 \mathrm{~K}$

\begin{tabular}{|c|c|c|c|c|c|}
\hline C11 & C12 & C44 & B & $\square$ & Ref. \\
\hline 19.9 & 7.4 & 9.1 & 11.6 & - & {$[27]$} \\
18.2 & 7.8 & 4.5 & 11.3 & - & {$[28]$} \\
19.3 & 8.5 & 6.0 & 12.00 & 5.584 & Present \\
\hline
\end{tabular}

Table 4. Average Grüneisen number $\left\langle_{1}^{j}\right\rangle_{L}$ for longitudinal wave, average square Grüneisen number $\left\langle\left(\gamma_{1}^{j}\right)^{2}\right\rangle_{L}$ and $\left\langle\left(\gamma_{1}^{j}\right)^{2}\right\rangle_{S}$ for longitudinal and shear wave and acoustic coupling constant for longitudinal $\left(D_{L}\right)$ and shear $\left(D_{S}\right)$ waves for FeAl from 323-1063K.

\begin{tabular}{|c|c|c|c|c|c|c|}
\hline $\begin{array}{c}\mathrm{T} \\
(\mathrm{K})\end{array}$ & $\left\langle\gamma_{\mathrm{i}}^{\mathrm{j}}>_{\mathrm{L}}\right.$ & $\left\langle\left(\gamma_{\mathrm{i}}^{\mathrm{j}}\right)^{2}>_{\mathrm{L}}\right.$ & $<\left(\gamma_{\mathrm{i}}^{\mathrm{j}}\right)^{2}>_{\mathrm{S}}$ & $\mathrm{D}_{\mathrm{L}}$ & $\mathrm{D}_{\mathrm{S}}$ & $\mathrm{D}_{\mathrm{L}} / \mathrm{D}_{\mathrm{S}}$ \\
\hline 323 & 0.566 & 1.317 & 0.844 & 10.086 & 7.592 & 1.33 \\
\hline 373 & 0.519 & 1.115 & 0.781 & 8.663 & 7.032 & 1.23 \\
\hline 423 & 0.473 & 0.935 & 0.723 & 7.345 & 6.509 & 1.13 \\
\hline 473 & 0.427 & 0.778 & 0.670 & 6.158 & 6.023 & 1.02 \\
\hline 573 & 0.338 & 0.525 & 0.580 & 4.214 & 5.156 & 0.82 \\
\hline 673 & 0.251 & 0.348 & 0492 & 2.876 & 4.424 & 0.65 \\
\hline 773 & 0.166 & 0.241 & 0424 & 2.059 & 3.820 & 0.54 \\
\hline 973 & 0.004 & 0.211 & 0.330 & 1.902 & 2.971 & 0.64 \\
\hline 1063 & -0.067 & 0.270 & 0.303 & 2.410 & 2.735 & 0.88 \\
\hline
\end{tabular}


In this way the structural stability, abrupt change in ductility at BDTT could be predicted on the basis of temperature variation of ultrasonic attenuation in the material from $373 \mathrm{~K}-1063 \mathrm{~K}$. Obtained results of the present investigation can be used for further study and applications.

\section{Conclusion}

On the basis of the obtained results in present investigation, we conclude that

a) Our theoretical approach for computation of second and third order elastic constants is justified and established for $\mathrm{B}_{2}$ structured intermetallic materials.

b) Born criterion for mechanical stability of $\mathrm{FeAl}$ is also satisfied on the basis of

c) $\mathrm{dC}_{\mathrm{ij}} / \mathrm{dT}$ is positive.

d) The ultrasonic velocities for longitudinal and shear waves increases with temperature.

e) The thermal relaxation time is found to be of the order of $10^{-13}$ second which is expected in other intermetallic TmSe [32]. So we can say that the chosen material $\mathrm{FeAl}$ relaxed back to its equilibrium position after $10^{-13}$ seconds.

f) Ultrasonic attenuation due to phonon- phonon interaction for longitudinal wave decreases suddenly near to temperature BDTT (473K). This shows anomalous changes at this transition temperature.

g) Ultrasonic attenuation due to thermal loss is negligible in comparison to loss due to phonon-phonon interaction.

\section{Acknowledgements}

Authors are thankful to Mr. Mohit Gupta and Mr. Punit Dhawan for fruitful discussion. Encouragement given by Prof S.K. Kor, Prof. B. P. Singh is also thankfully acknowledged.

\section{REFERENCES}

[1] Y. X. Tian, J. T. Guo, L. Y. Sheng, G. M. Cheng, L. Z. Zhou, L. L. He, H. Q. Ye, Microstructures and mechanical properties of cast $\mathrm{Nb}-\mathrm{Ti}-\mathrm{Si}-\mathrm{Zr}$ alloys, Intermetallics, Vol. 16, No. 6, 807-812, 2008.

[2] T. Dasgupta, A. M. Umarji, Improved ductility and oxidation resistance in $\mathrm{Nb}$ and $\mathrm{Al}$ co-substituted $\mathrm{MoSi}_{2}$, Intermetallics, Vol. 16, No. 6, 739-744, 2008.

[3] T. Jianfeng, H. Wangyu, Y. Jianyu,W. Yurong, Anharmonic effects on B2-FeAl(110) surface: A molecular dynamics study, Applied Surface Science, Vol. 254, No. 5, 1475-1481, 2007.

[4] V. N. Antonov, O. V. Krasovska, E. E. Krasovskii, Y. V.
Kudryavtsev, V. V. Nemoshkalenko, B. Y. Yavorsky, Y. P. Lee, K. W. Kim, Experimental and theoretical study of the optical properties of FeAl alloy, Journal of Physics: Condensed Matter, Vol. 9, No. 50, 11227-11238, 1997.

[5] N. S. Sauthoff, Iron aluminides:present status and future prospects, Material Science Engineering A, Vol. 258, No. 1-2, 1-14, 1998.

[6] N. S. Stoloff, V. K. Sikka, in: Physical Metallurgy and Processing of Intermetallic Compounds, Chapman and Hall, New York, 1996.

[7] J. H. Westbrook, R. L. Fleischer, Intermetallic Compounds Principles,Vol. 1, John Wiley \& Sons, Inc., New York, 1994.

[8] S.C. Deevi, V.K. Sikka, Nickel and Iron aluminidess: an overview on properties, processing and application, Intermetallics, Vol. 4, No. 5, 357-75, 1996.

[9] P.J. Mazsiaz, G.M. Goodwin, D.J. Alexander, S. Viswanathan. Nickel and Iron Aluminides: Processing, Properties, and Applications, S.C. Deevi, P.J. Maziasz, R.W. Cahn (Eds.), pp. 157-176, ASM International, Materials Park, $\mathrm{OH}, 1997$.

[10] T. B. Massalski, Binary alloy phase diagrams. p. 112, ASM International, Metals Park, OH, 1986.

[11] C.G. McKamey, J.H. DeVan, P.F. Tortorelli, V.K. Sikka, A review of recent developments in $\mathrm{Fe}_{3} \mathrm{Al}$-based alloys, Journal of Materials Research, Vol. 6, No. 8, 1779-1805, 1991.

[12] Y.V.R.K. Prasad, D.H, Sastry, S.C. Deevi, Hot masking behaviour of extruded power products of $\mathrm{B}_{2}$ iron aluminides alloys, Materials Science \& Engineering A Vol. 311, No.1, 42-53, 2001.

[13] R. Sitek, J. Kaminiski, P. Sallot, K. J. Kurzydlowski, Structure and properties of iron aluminide layers fabricated by the chemical vapour deposition on $316 \mathrm{~L}$ steel, Materials Science-Poland, Vol. 28, No. 1, 163-172, 2010.

[14] D. Singh, D. K. Pandey, P. K. Yadawa, A. K. Yadav, Attenuation of ultrasonic waves in $\mathrm{V}, \mathrm{Nb}$ and $\mathrm{Ta}$ at low temperatures.Cryogenics Vol. 49, No. 1, 12-16, 2009.

[15] D. Singh, P. K. Yadawa, Effect of Platinum addition in coinage metals on their ultrasonic properties, Platinum Metals Review, Vol. 52, No. 3, 172-179, 2010.

[16] K. Brugger, Thermodynamic definition of higher order elastic coefficients. Physical Review, Vol. 133, No. 6A, A1611-A1612, 1964.

[17] R. R. Yadav, D. Singh, Ultrasonic attenuation in lanthanum monochalcogenides, Journal of the Physical Society of Japan, Vol. 70, No. 6, 1825-1832, 2001.

[18] S. Mori, Y. Hiki, Calculations of third order elastic constants and forth order elastic constants of alkali halides crystals, Journal of the Physical Society of Japan, Vol. 45, No. 5 , 1449-1456, 1978.

[19] P. B. Ghate, Third-order elastic constants of alkali halide crystals, Physical Review Vol. 139, No. 5A, A1666-A1674, 1965.

[20] M. P. Tosi, Cohension of ionic solids in the Born model. In: F. Seitz and D. Turnbull eds), Solid State Physics, Vol. 16, pp. 
1-120. Academic Press, New York, 1965

[21] W. P. Mason, Physical Acoustics, Vol. IIIB, Academic Press, New York, 1965.

[22] W. P. Mason, T. B. Bateman, Relation between third order elastic moduli and thermal attenuation of ultrasonic waves in nonconducting and metallic crystals, Journal of the Acoustical Society of America, Vol. 40, No. 4 , 852-862, 1966.

[23] H. Siethoff, Debye temperature, self-diffusion and elastic constants of intermetallic compounds, Intermetallics Vol. 5, No. 8, 625-632, 1997.

[24] B.V. Reddy, S.C.Deevi, Thermophysical properties of FeAl (Fe-40 at.\%Al), Intermetallics, Vol. 6, No. 12, 1369-1376, 2000.

[25] D. E. Gray (ed.), AIP Handbook, third edition, McGraw Hill, New York, 1956.

[26] B. Lal, N. Subramanam, Heat and Thermodynamics, S.Chand and Co., New Delhi, 1998.

[27] S. H. Yang, M. J. Mehl, D. A. Papaconstantopoulos, M. B. Scott, Application of a tight-binding total-energy method for Fe-Al, Journal of Physics: Condensed Matter, Vol. 14, No. $8,1895-1902,2002$.

[28] H. J. Leamy, E. D. Gibson, F. Kayser, The elastic stiffness coefficient of iron-aluminium alloys-I experimental results and thermodynamic analysis, Acta Metallurgica, Vol. 15, No. 12, 827-1838, 1967.

[29] N. Junqua, J. C. Desoyer, Germination de dislocations hélicoïdales-méthode générale de calcul. application á l'alliage Fe A 140 trempé, Acta Metallurgica, Vol. 30, No. 2,
395-401, 1982.

[30] R. R. Yadav, D. Singh, Behaviour of ultrasonic attenuation in intermetallics, Intermetallics Vol. 9, No. 3, 189-194, 2001.

[31] D. Singh, D. K. Pandey, Ultrasonic investigation in intermetallics, Pramana Vol. 72, No. 2 , 389-398, 2009.

[32] D. Singh, D. K. Pandey, P. K. Yadawa, Ultrasonic wave propagation in rare-earthmonochalcogenides, Central European Journal of Physics, Vol. 7, No. 1, 198-205, 2009.

[33] D. Singh, D. K. Pandey, D. K. Singh, R. R. Yadav, Propagation of ultrasonic waves neptunium monochalcogenides, Applied Acoustics Vol. 72, No. 10, 737-741, 2011.

[34] D. Singh, S. Tripathi, D. K. Pandey, A. K. Gupta, D. K. Singh, J. Kumar, Ultrasonic wave propagation in semimetallic single crystals, Modern Physics Letters B, Vol. 25, No. 31, 2377-2390, 2011.

[35] R. P. Singh, M. P. Singh, P. C. Srivastava, R. K. Singh, Temperature dependent acoustical characterization of alkaline earth monochalcogenides in B1 and B2 phase, Physica B 405, No. 1, 77-84, 2010.

[36] N. S. Stoloff, V. K. Sikka (eds.), Physical metallurgy and processing of intermetallic compounds, Chapman \& Hall, New York, 1996.

[37] D. Risanti, J. Deges, L. Falat, S. Kobayashi, J. Konrad, M. Palm, B. Potr, A. Schneidr, C. Stallybrass, F. Stein, Dependence of the brittle-to ductile transition temperature(BDTT) on the $\mathrm{Al}$ content of Fe-Al alloys. Intermetallics Vol. 13, No. 12, 1337-1342, 2005. 